\title{
Percurso das almas numa apreciação semiótico-discursiva
}

\author{
José Leite Junior ${ }^{1}$ \\ http://lattes.cnpq.br/1037793897092173
}

Enviado em: 31/08/2018

Aceito em: 20/11/2018

RESUMO: Este artigo apresenta uma abordagem semiótico-discursiva sobre o Auto da Alma, peça de Gil Vicente apresentada à família real portuguesa em 1518. Essa peça teatral, assim como a chamada Trilogia das Barcas, do mesmo dramaturgo, costuma ser considerada uma alegoria da transição da vida física para o plano espiritual. $\mathrm{Na}$ análise são consideradas as estratégias de manipulação, segundo Greimas e Courtés (2008) empregadas pelo adjuvante e oponente em seu fazer persuasivo. O estudo também leva em consideração as propostas teórico-metodológicas tanto da semiótica das paixões (GREIMAS e FONTANILLE, 1993), como da semiótica tensiva (FONTANILLE e ZILBERBERG, 2001; ZILBERBERG, 2011). Os achados mais relevantes a análise permitem constatar uma adesão enunciativa aos valores ideológicos do contexto histórico. O discurso é marcado pela correção inversa entre o andamento intenso e acelerado do programa divino e o retardo atenuante e extensivo do contraprograma diabólico. Além disso a Igreja Católica é configurada como espaço de triagem moral e de reiteração da regra e da autoridade.

Palavras-chave: teatro vicentino; manipulação; discurso; semiótica.

ABSTRACT: This article presents a semiotic-discursive approach on the Auto da Alma, a play by Gil Vicente exhibited to the Portuguese royal family in 1518. This play, as well as the so-called Trilogia das Barcas, by the same playwright, is often considered an allegory of the transition from physical to spiritual life. In the analysis are considered manipulation strategies, according to Greimas and Courtés (2008) employed by the adjuvant and opponent in their persuasive doing. The most relevant findings of the analysis allow us to note an enunciative adherence to the ideological values of the historical context. The discourse is marked by the inverse correction between the intense and accelerated progress of the divine program and the attenuating and extensive delay of the diabolic counterprogram. Moreover, the Catholic Church is configured as a space for moral screening and reiteration of rule and authority.

Keywords: dramaturgy of Gil Vicente; manipulation; discourse; semiotics.

Faço, neste artigo, considerações semiótico-discursivas ${ }^{2}$ sobre o Auto da Alma, de Gil Vicente. Juntamente com a Trilogia das Barcas ${ }^{3}$, essa peça alegoriza a transição do plano existencial para o espiritual como uma locomoção ${ }^{4}$.

No Auto da Alma, assim como na Trilogia das Barcas, os costumes e valores ideológicos

\footnotetext{
${ }^{1}$ Universidade Federal do Ceará,

E-mail: leiteufc@gmail.com

2 Para tanto, utilizo ferramentas teórico-metodológicas fundadas por Algirdas Julien Greimas.

3 Auto da Alma (1518), o Auto da Barca do Inferno (1517), o Auto do Purgatório (1518) e o Auto da Barca da Glória (1519).

${ }^{4}$ Sobre o conceito de alegoria, apoio-me em Ceia (1998). No entanto, não é objetivo deste trabalho empreender uma análise retórica, no sentido tradicional da palavra.
} 
do reinado de D. Manuel $I^{5}$ são reiterados ${ }^{6}$. A pequena peça confirma as formas discursivas valorizadas nesses primeiros anos do século dezesseis, sendo notáveis as inserções interdiscursivas, como aquelas relacionadas com a Bíblia, em particular o Novo Testamento $^{7}$, e as hagiografias ${ }^{8}$, e também intersemióticas, pela citação de cantos litúrgicos.

No plano da manifestação textual, a peça propõe uma alegoria de feição aparentemente simples, que vem explicitada no paratexto (argumento). A Igreja é personificada como a "estalajadeira das almas", cabendo-lhe acolher a alma peregrina e prover o alimento necessário à reposição das forças necessárias para prosseguir rumo ao reino celestial:

Assi como foi cousa muito necessária haver nos caminhos estalagens, pera repouso e refeição dos cansados caminhantes, assi foi cousa conveniente que nesta caminhante vida houvesse uma estalajadeira, pera refeição e descanso das almas que vão caminhantes pera a eternal morada de Deus. Esta estalajadeira das almas é a Madre Santa Igreja, a mesa é o altar, os manjares as insígnias da Paixão. E desta perfiguração trata a obra seguinte.

Em síntese, o auto começa com a apresentação da Madre Igreja, a estalajadeira, e de seus santos doutores, com a mesa sagrada pronta. Em seguida, aparece a Alma, que vem com o Anjo Custódio. No trajeto, no entanto, o primeiro Diabo que se esforça por desviála do caminho da salvação. A caminhada vai ter na hospedaria da Madre Igreja, quando a Alma ainda sofre assédio, desta feita pelo segundo Diabo, mas a ele resiste, pois já tem a proteção da Igreja. A Alma é servida de quatro iguarias (o açoite, a coroa de espinhos, os cravos e o corpo de cristo), ministradas pelos santos doutores, Agostinho, Ambrósio, Jerônimo e Tomás entre cantos litúrgicos. Terminada a páscoa, os presentes se dirigem cantando para a adoração do túmulo de Jesus Cristo.

Considerada como forma discursiva que não faz exceção à dramaturgia em geral, o auto desenvolve uma interlocução de vozes que põem em disputa seus valores e crenças. Confrontando dois contratos, a polêmica contrapõe um programa identificado com os valores eufóricos sustentados pelo enunciador pressuposto (visão de mundo do autor) a um contraprograma, representativo dos valores disfóricos.

Ao Anjo Custódio cabe comunicar os valores celestiais; aos Diabos, reiterar os valores mundanos. Sendo os anjos, celestiais ou infernais, mensageiros, cabelhes constituir no espírito humano a virtualização de um objeto de valor. Segundo o programa, o objeto proposto ao espírito humano é a salvação, ou seja, a conjunção com os valores celestiais; segundo o contraprograma, o objeto proposto é a negação da espiritualidade e a afirmação dos valores mundanos.

Para conquistar a adesão espiritual aos respectivos valores, cada mensageiro empreende um esforço de manipulação. Como propõem Greimas e Courtés (2008, p. 300), a manipulação costuma ser estabelecida de quatro maneiras, dependendo de estar o foco semântico

\footnotetext{
5 O rei Dom Manuel I foi soberando de Portugal entre 1469 e 1521.

${ }^{6}$ O rei Dom Manuel I foi soberando de Portugal entre 1469 e 1521. No capítulo LIV de sua crônica sobre o rei, Damião de Góis (1749) entra em pormenores sobre a pessoa e os hábitos do rei. Na página 644 desse capítulo, há um flagrante dos hábitos reais por ocasião da semana santa.

${ }^{7}$ Sobretudo ganha relevo o simbolismo da comunhão: Mateus 26: 17-30; Marcos 14: 12-26; Lucas 22: 7-39; João 1318:1. Com exceção do Evangelho Segundo João, que enfatiza as orações, revelações e instruções verbais de Cristo, no último versículo de cada versão evangélica aparece o que se ritualizaria como eucaristia, que culmina com o canto de um hino, quando Jesus se retira com os apóstolos para o Monte das Oliveiras.

${ }^{8}$ Entre as personagens, estão os doutores da Igreja: Santo Agostinho, Santo Ambrósio, S. Jerônimo e S. Tomás de Aquino.
}

(1) 
no sujeito a ser persuadido ou no objeto em negociação. Estando a ênfase no sujeito a ser persuadido, a este podem ser atribuídos valores euforizantes, caracterizandose assim a sedução, ou valores disforizantes, caracterizando-se a provocação. ${ }^{9}$ Se a ênfase insidir sobre o objeto oferecido, haverá tentação se tal objeto for euforizado; e haverá intimidação se houver a sugestão de privação do objeto de valor.

Cabe ressaltar, a propósito da manipulação, a singularidade discursiva do Auto da Alma, se comparada às peças que constituem a Trilogia das Barcas. Na peça em apreço, enfatiza-se o querer como modalizador contratual. Sabendo-se que o querer é individualizante, fica explicada a estratégia discursiva que coloca em foco o trajeto de uma só personagem, considerando-se o programa de transição entre o mundo material e o espiritual. $\mathrm{Na}$ Trilogia das Barcas, esse trânsito é coletivo, apresentado como fato consumado, cujo teor é revelado ao enunciatário a cada depoimento nas interlocuções individuais. A ênfase do Auto da Alma é a manipulação; já o da Trilogia das Barcas é a sanção.

A bem da clareza, ressalto que o contrato e a sanção constituem fases do percurso narrativo canônico (GREIMAS; COUTÉS, 2008, p. 334-336), que se desenvolve nesta sequência: contrato, competência, desempenho e sanção. Cada uma dessas fases se caracteriza por certas modalizações, considerando-se como modalização a sobreposição de um enunciado sobre outro ${ }^{10}$. Na fase do contrato, a modalização típica é de um fazer sobre um fazer: para o bem ou para o mal, o manipulador age segundo um fazer-fazer, já que tenta convencer alguém a fazer algo.

Passo agora a uma descrição das diversas investidas manipulatórias, que marcam os enunciados assumidos pelo Anjo Custódio e o primeiro Diabo ${ }^{11}$.

Logo após a cena de apresentação, aparece a Alma andarilha. Vendo que ela vai cansada e sonolenta, o Anjo Custódio lhe diz:

\author{
Planta sois e caminheira, ${ }^{12}$ \\ que ainda que estais, vos is \\ donde viestes. \\ Vossa pátria verdadeira \\ é ser herdeira \\ da glória que conseguis: \\ andai prestes. \\ Alma bem-aventurada, \\ dos anjos tanto querida, \\ não durmais!
}

$\mathrm{Na}$ designação da Alma, percebe-se uma conexão isotópica ${ }^{13}$ aparentemente

\footnotetext{
${ }^{9}$ São eufóricos os valores que contam que confirmam a crença e o interesse do enunciador, seja este pressuposto à enunciação (autoria), seja ele circunscrito no enunciado (personagem). Os valores disfóricos são aqueles negados por essas vozes.

${ }^{10}$ Há enunciados de estado, caracterizado pela conjunção ou disjunção de um sujeito com um objeto, e enunciados de fazer, em que um sujeito entre em conjunção (aquisição) ou em disjunção com um objeto (privação). Exemplos de modalização: se um enunciado de saber modaliza um enunciado de fazer, constitui-se um saber-fazer (aquisição de uma habilidade, aprendizagem); se um fazer modaliza um saber, resulta um fazer-saber (como ocorre no ensino ou numa receita de bolo).

${ }^{11}$ Enquanto o primeiro Diabo desenvolve seu assédio na caminhada, com várias investidas, o segundo Diabo, encontrando a Alma já na hospedaria, é por ela imediatamente repelido.

${ }^{12}$ Verso 50. Para facilitar a localização, indicarei somente o número do primeiro verso de uma dada sequência.

${ }^{13}$ Isotopia é uma reiteração semântica ao longo de um enunciado. Uma conexão isotópica ocorre quando uma única lexicalização reúne duas ou mais isotopias. No caso destacado, "planta” faz convergir semas relativos ao vegetal (fixo à terra) como ao animal (embora se desloque, está parado).
} 
incompatível, já que a "planta" está fixa na terra e, sendo "caminheira", a semântica vegetal cruza com a animal, caracterizado pela mobilidade. O fato é que a aparente incompatibilidade semântica sugere um recolhimento de semas ligados à terra, à estaticidade e à morte. Sendo vegetal, a planta tanto cresce para o céu como o chão, sendo também contrários seus movimentos. Sendo caminheira, então ela não está presa, podendo decidir a direção e o sentido a seguir. Obviamente, o vegetal não foi inaugurado no texto de Gil Vicente. A árvore é uma lexicalização recorrente na Bíblia, sendo as primeiras ocorrências aquelas do primeiro livro do Pentateuco ${ }^{14}$. No consumo das árvores permitidas, Adão e Eva permaneceriam em seu estado paradisíaco; mas, no consumo da árvore do conhecimento, a disjunção com o paraíso deu início à peregrinação. Em sua manipulação, o Anjo Custódio nega o estado vegetativo, preso ao reino terreno, e promete o reino celeste, a "pátria verdadeira". Se ele oferece um objeto de valor eufórico, o Anjo Custódio lança mão da tentação. E, ao dizer que é verdadeira a pátria, ele busca consolidar a fidúcia, sem a qual os valores da contratação não se atualizam. Se a pátria é verdadeira, então ela tanto é como parece uma pátria, do que se deduz que negar a vida terrena (vegetal) implica afirmar esse teor de verdade. Assim, a narratividade sugerida pela persuasão do Anjo Custódio descreve uma dêixis que nega o parecer e afirma o ser, a imanência da verdade, fazendo lembrar que a Alma é "herdeira / da glória", ou seja, do legado deixado pelo sacrifício do Jesus Cristo: a alma é herdeira da Graça.

Do ponto de vista tensivo, a conexão isotópica da "planta" pode ser entendida como uma concessão, que Zilberberg (2011, p. 242) reputa com "chave de sentido":

\begin{abstract}
A concessão é certamente um dos principais capítulos da semiótica do acontecimento, desde que a concebamos como produto das subvalências de andamento e tonicidade quando atingem o paroxismo, ou seja, a desmedida. Como ocorre com a maioria das teorias que encontram alguma ressonância antes de desaparecer, a concessão põe o "acento de sentido" numa figura gramatical modesta, apenas uma figura entre as demais, mas que se encontra aqui - circularmente - destacada e promovida ao nível de chave do sentido, parcial ou total, conforme o caso.
\end{abstract}

A aparente simples figura da planta na verdade sintetiza a investida do enunciador, que espera uma implicação: se o humano é imagem e semelhança de Deus e tem a Graça proporcionada por Jesus Cristo, então ela deve buscar acelerada e intensamente a salvação. Mas o que o Anjo Custódio constata é a concessão, o "contratempo do sujeito" (ZILBERBERG, 2011, p. 243), que, embora tenha recebido esses atributos, não se lança com o empenho esperado para superar as limitação terrenas.

Em resposta, a Alma, confessando-se fraca, reconhece o papel adjuvante do Anjo e reitera o compartilhamento dos valores celestiais:

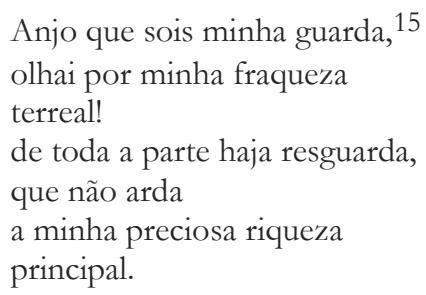

\footnotetext{
${ }^{14} \mathrm{E}$ o Senhor Deus fez brotar da terra toda a árvore agradável à vista, e boa para comida; e a árvore da vida no meio do jardim, e a árvore do conhecimento do bem e do mal. (Gênesis 2:9)

15 Verso 71.
} 
Feito isso, o Anjo da Guarda virtualiza o percurso glorioso, reiterando as competências necessárias para um desempenho de sucesso. O Anjo Custódio afirma sua própria competência de guardião, investindo argumentativamente na fidúcia, conditio sine qua non da fase contratual do percurso narrativo ("Continuarei ter o cuidado / no fim de vossa jornada"16). Trata-se de uma extensão contratual, portanto a manipulação continua, inclusive com o recurso da variante da intimidação, já que a inobservância das competências levaria a uma virtual perda da salvação:

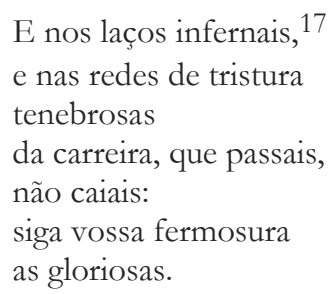

Mas, como adiantava-se no caminho o Anjo Custódio, o primeiro Diabo aproveita para fazer sua investida, que começa com este conjunto de versos:

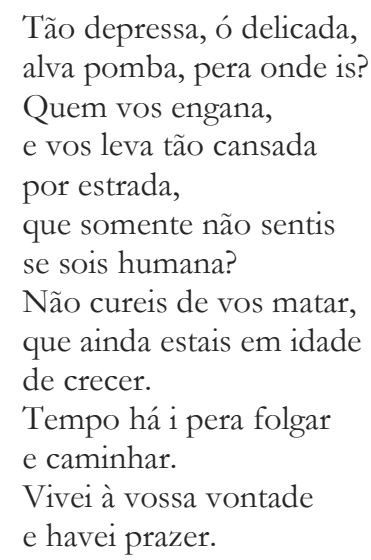

O trecho acima apresenta duas variações do fazer persuasivo. O primeiro é o recurso da sedução, já que o Diabo dissimula cortesia e trata a Alma como "delicada, alva pomba". Como o contrato pressupõe fidúcia, o Diabo, que finge não saber o destino da Alma, mostra-se solidário para com o cansaço da peregrina. Lançando juízos disfóricos sobre os sacrifícios requeridos na caminhada, o Diabo mais uma vez seduz a Alma, euforizando seus atributos humanos e terrenos. E arremata com a tentação, propondo a conjunção com o prazer de viver, ou seja, opera argumentativamente sobre o querer fazer da Alma ("em idade / de crecer") em detrimento do dever fazer e seus sacrifícios intrínsecos. Responsável pelo contraprograma, o Diabo sebrepõe o querer sobre o dever. Após uma série de variações do recurso argumentativo da tentação, ele conclui:

Senhora, vós sois senhora ${ }^{18}$

emperadora,

não deveis a ninguém nada.

Sede isenta.

\footnotetext{
16 Verso 127

17 Verso 134.

18 Verso 195
} 

o dever:

Eis que o Anjo Custódio, percebendo o atraso da Alma, chama-lhe atenção para

\author{
Oh! andai; quem vos detém? ${ }^{19}$ \\ Como vindes pera a Glória \\ devagar! \\ Ó meu Deus! Ó sumo bem! \\ Já ninguém \\ não se preza da vitória \\ em se salvar!
}

Na polêmica entre a contratação do programa e do contraprograma, há uma disputa entre o dever, que confirmaria o desempenho do sujeito, e o querer, que configuraria um antissujeito. As intervenções do Anjo Custódio e do primeiro Diabo, que culminam com a chegada à hospedaria, constituem variações figurativas sobre esses dois eixos temáticos: a virtualização pelo dever impõe a heteronomia; e a virtualização pelo querer sugere a autonomia.

O Anjo Custódio quer a aceleração, o restabelecimento e o recrudescimento da marcha, de modo a imprimir ao andamento da Alma o que Zilberberg (2011, p. 277) descreve como "ascendência tensiva": "Pelo restabelecimento, o sujeito se desprende, se libera da atonia". Por sua vez, o Diabo luta pela atonia, o que implicaria a "perda irreversível das competências modais", como observa o mesmo semioticista (ZILBERBERG, 2011, p. $240)^{20}$. Nesse embate tensivo, o esforço persuasivo do Anjo Custódio anseia a verticalidade ascendente da glorificação celestial, a abreviação do tempo - a intensidade, enfim. Já o Diabo procura imprimir a horizontalidade terrena, o descanso e, se possível o desfrute material, a dilatação do texto - a extensidade, portanto. É possível visualizar paradigmaticamente esse "espaço tensivo" em dois eixos, conforme instrui Zilberberg (2011, p. 253):

(i) na linha das ordenadas, um eixo da intensidade sobre o qual incidem os estados de alma que afetam o sujeito;

(ii) na linha das abscissas, um eixo de extensidade sobre o qual incide a consistência variável dos estados de coisas.

É notável, pelas reiterações do texto, no tocante ao estado da Alma²1, seu cansaço, que outra coisa não é senão a manifestação de resistência ao andamento acelerado (a concessão já referida), no que recebe como adjuvante o Diabo, que, agente do contraprograma, procura ressaltar o apego às coisas materiais, oferecendo à peregrina objetos que sensibilizem sua vaidade: "Vesti ora este brial"22; "Uns chapins haveis mister / de Valença: ei-los aqui"23. O Diabo não deixa de reforçar a tentação com um juízo elogioso, quando diz "Agora estais vós fermosa / como a rosa" 24 , e, revelando seu intento, propõe a parada, o retorno à atonia: "Descansai." 25

\footnotetext{
${ }^{19}$ Verso 199.

20 Zilberberg percebe isso num dos poesmas de As flores do mal, de Baudelaire, iintitulao "O gosto do nada".

${ }^{21}$ Peço vênia pela inevitável redundância.

22 Verso 227.

23 Versos 234-235.

24 Versos 243-244.

${ }^{25}$ Não seria ocioso destacar o segundo sentido de "atonia”, do Caldas Aulete, que bem expressa a tensão emocional da Alma: "2. Em estado de desorientação mental, confuso, perturbado, sem saber o que dizer ou fazer; ATARANTADO; ATURDIDO; DESNORTEADO [F.: do lat. attonitus, a, um.]”
} 
Mas, ao contrário de facilitar a caminhada, os objetos recebidos acabam por tornar ainda mais penosa a caminhada. Vendo a Alma em repouso e ainda inconvenientemente elegante, o Anjo Custódio a repreende. Recuperando sua missão contratual, ele lança mão da intimidação, ao apontar a iminência da condenação ao inferno: "Ó Alma, is-vos perdendo! / Correndo vos is meter / no profundo!” Manipula também pela tentação, já que virtualiza um objeto de alto valor espiritual: “[...] Virgem gloriosa / vos espera"26. E ainda manipula por provocação, quando põe em dúvida a competência veridictória da Alma, que não parece capaz de distinguir a "pátria vera": "Enjeitais a glória vossa / e pátria vera!"27 A Alma, na avaliação do Anjo Custódio, não percebe a artimanha da mentira, ou seja, o que parece, mas não é: o ilusório paraíso terreno.

Mas o Diabo é obstinado. Alegando a juventude da Alma, reitera não ter sentido sua pressa e investe com novas tentações, como a riqueza e a prosperidade:

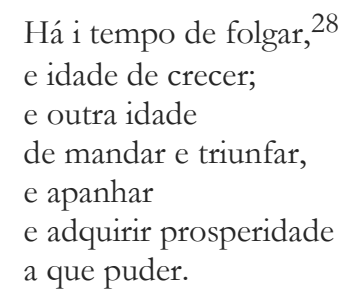

No rol de objetos virtualizados mediante a manipulação pela tentação, sincretiza-se a riqueza (ouro) com a realização afetiva (casamento), valendo lembrar que essa conexão isotópica da "aliança" tanto recolhe semas da prosperidade, pelo valor do metal, como da realização afetiva, pela conjunção afetiva. No trecho, como a sugerir a inversão moral subjacente à tentação, não deixa de ser curiosa a inversão da ordem entre "casar / e namorar", uma coordenação sintática, mas uma recção duvidosa do casamento sobre o namoro, concessivamente inversos no plano do conteúdo, arranjo de palavras que dificilmente se sustentaria por motivos exclusivos de metrificação:

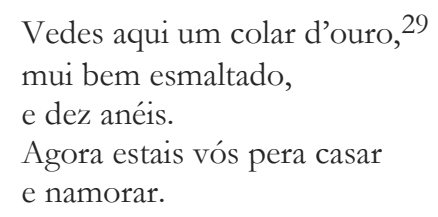

O Diabo, com esse novo assédio, logra a adesão da Alma, ainda que momentaneamente: “Oh! Como estou preciosa, / tão dina pera servir. / E santa pera adorar!" Percebese, na interlocução, que a Alma mostra-se jubilosa, sentindo-se até merecedora de idolatria.

Examinando o estado da Alma à luz do percurso passional canônico proposto por Greimas e Fontanille (1993, p. 155), que compreende a disposição, a sensibilização, a emoção e a moralização, ela é flagrada na etapa da emoção ${ }^{30}$. Não tarda, pois, a moralização,

\footnotetext{
26 Verso 261-262.

27 Versos 265-266.

28 Verso 281.

${ }^{29}$ Verso 302.

30 Tomei como base a primeira versão do percurso passional canônico, mesmo reconhecendo que esse esquema analítico vem sendo reelaborado. Dada a simplicidade passional do texto, não vejo motivos para reexaminar as versões. Assim se lê em Greimas e Fontanille (1993, p. 155): "A moralização intervém em fim de sequência e recai sobre o conjunto da sequência, mas mais particularmente no comportamento observável. Ela pressupõe, portanto, a
} 
com o retorno do Anjo Custódio. Com nova admoestação, ele procura corrigir o excedente passional (e material) da Alma, restaurando a ordem moral exigida pelo programa divino, segundo o qual a implicação deve vigorar sobre a concessão. Conforme Zilberberg (2011, p. 244), “Admitiremos que os sintagmas implicativos reportam-se à gramaticalidade das regras e os sintagmas concessivos, ao acontencimento, ou seja, ao sucesso de um contraprograma, conforme o caso, desastroso ou salvador para o sujeito." Guardião do programa divino, o Anjo Custódio reage com energia:

Ó Alma despiedosa ${ }^{31}$
perfiosa!
Quem vos devesse fugir,
mais que guardar!
Pondes terra sobre terra,
que esses ouros terra são.

A realção da Alma é a confissão de sua "fraca natureza", ou seja, sua competência de prosseguir rumo à glória sem ajuda. Faltam-lhe o poder, como manifesta seu cansaço, e o saber, por sua fraqueza em distinguir entre o parecer e o ser nas investidas diabólicas. Desenha-se semanticamente uma dualidade: uma corpórea (cansaço) e uma espiritual (fraqueza). É o momento em que o Anjo Custódio anuncia a proximidade da estalagem, onde a Igreja estalajadeira, com seus santos Doutores, poderá revigorá-la na transição definitiva dos valores corpóreos para os espirituais. Tal transição granha significativo revestimento figurativo alegórico, com reiteradas conexões isotópicas entre isotopias do corpo e do espírito, que culminam na eucaristia.

Estando, enfim, sob a assistência da hospedeira, a Alma faz uma demorado mea-culpa, que assim começa:

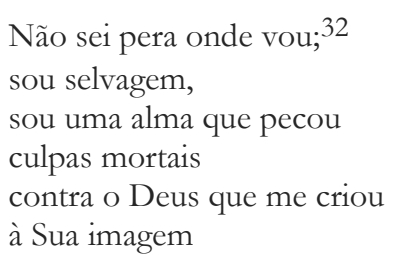

A alma, que esteve atônita ${ }^{33}$, a ponto de desistir da salvação, faz sua contrição. Discursivamente, manifesta sua disposição para aderir aos valores contratuais do programa divino, ressaltando-se que o contrato não se efetiva sem um compartilhamento de valores e uma fidúcia (fé). O querer se ajusta ao dever; no entanto, falta-lhe o saber e o poder para a prova glorificante (não cair mai em tentação). Para tais atributos concorre a Igreja, como hospedeira, e a palavra e o canto ministrados pelos Doutores. Percebe-se que não há um contato

manifestação patêmica, denominada emoção, cuja aparição no discurso assinala que a junção tímica está cumprida, dando a palavra ao corpo próprio. A sensibilização é pressuposta pela emoção: é a transformação tímica por excelência, a operação pela qual o sujeito discursivo tranforma-se em sujeito que sofre, que sente, que reage, que se emociona. Ela própria pressupõe essa programação discursiva que denominamos disposição, e que resulta da convocação dos dispositivos modais dinamizados e selecionados pelo uso; ela aciona uma aspectualização da cadeia modal e um "estilo semiótico' característico do fazer patêmico."

31 Verso 320.

32 Verso 434.

${ }^{33}$ Não seria ocioso destacar o segundo sentido de "atonia", do Caldas Aulete, que bem expressa a tensão emocional da Alma: "2. Em estado de desorientação mental, confuso, perturbado, sem saber o que dizer ou fazer; ATARANTADO; ATURDIDO; DESNORTEADO [F.: do lat. attonitus, a, um.]” 
direto entre a Alma e Deus, que se mantém sempre pressuposto ao fazer discursivo de seus emissários. A palavra provém do enunciador pressuposto, consubstanciado como um alimento, sendo servido pela Igreja e aqueles que são doutos no trato desse alimento espiritual, intérpretes autorizados no trato da palavra divina:

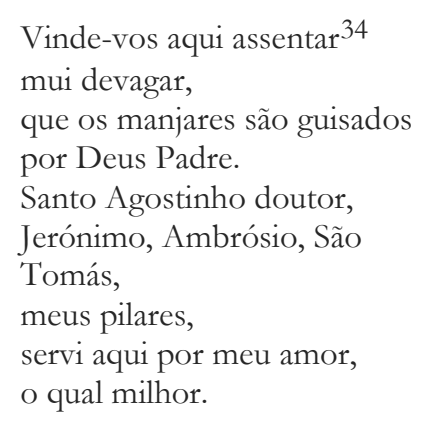

Vale lembrar que as competências para o fazer glorificante decorre das modalizações do poder e do saber. O saber é ministrado pelos Doutores, que propõem, intérpretes autorizados que são, quatro iguarias constitutivas do poder necessário para instrumentalizar a Alma em seu percurso rumo à glorificação. São oferecidos quatro alimentos, cada um colocado em sincretismo intersemiótico, já que vêm associados a cantos litúrgicos: o primeiro alimento são os açoites, momento em que se canta "Ave, flagellum"; o segundo é a coroa de espinhos, que se oferece ao som de "Ave, corona spinarum"; o terceiro são os cravos, acompanhado por "Dulce lignum, dulcis clavus"; e o quarto é o corpo de Cristo, quando é cantado "Domine Jesu Christe".

A reiteração figurativa dos cantos litúrgicos contribui para o efeito de sentido de transição do plano material para o espiritual. A intensidade ascendente, que encontrava a resistência corporal concessiva, já tende à transcendência implicativa. O papel do Anjo Custódio, que imprimiu à ascendência um adnamento rápido, caracteriza-se como uma sublimação, segundo a terminologia tensiva de Zilberberg (2011, p. 121). Em oposição à mistura com os valores da materialidade, soprepõe-se uma triagem, operação que Zilberberg (2011, p. 290) associa ao sagrado, apoiado em Cassirer. Isso confere especial sentido ao espaço reservado da hospedaria, recortado do mundo (profano), onde se opera a triagem, a separação entre o joio e o trigo:

O regime de exclusão tem por operador a triagem e, se o processo atinge seu termo, leva à confrontação contensiva do exclusivo e do excluido e, para as culturas e as semióticas que são dirigidas por esse regime, à confrontação do "puro" e do "impuro". (FONTANILLE; ZILBERBERG, 2001, p. 29)

Oferecidas as quatro iguarias purificantes - a Páscoa católica -, Santo Agostinho convida os presentes a colher a fruta do jantar:

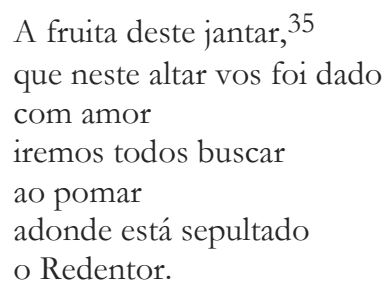

34 Verso 506.
${ }^{35}$ Verso 819. 
Numa peça apresentada "em a noite de Endoenças" - a quinta-feira santa -, reconhece-se a analogia com a instauração da própria Igreja. A alegoria recupera analogicamente as isotopias evangélicas que relacionam a vida como via dolorosa, tendo inclusive Jesus lavado os pés dos discípulos, que são almas peregrinas, no intuito de lhes restaurar as forças de um corpo cansado em seu poder e fraco em seu saber. Após a ceia, segundo os evangelhos de Mateus, Marcos e Lucas, os discípulos entoaram cantos, dirigindo-se ao Monte das Oliveiras. No auto em apreço, terminada a ceia, os presentes vão buscar o fruto (sobremesa) no túmulo de Cristo, e o fazem cantando "Te Deum laudamus".

Antes de encerrar estas considerações semióticas, chamo atenção para uma significativa isotopia relativa ao termo complexo masculino-feminino. Do lado feminino, está a Alma, a Igreja e, de forma indireta, a Virgem Maria. A Alma representa a peregrinação humana em busca da santificação, não sendo supérfluo considerar que o pecado remonta ao traço feminino, a partir de Eva. A Igreja aparece como hospedeira, ligada, pois, aos serviços de assistência espiritual, cabendo-lhe a restauração dos que se enfraqueceram pelo pecado. Quanto à Virgem Maria, esta é apresentada pela maternidade dolorosa, que, tendo vivenciado o sacrifício do filho, foi glorificada. Já do lado masculino estão os demônios e o Anjo Custódio, que disputam a condução da Alma pelo caminho ou descaminho, cumprindo, segundo o programa a que são fiéis, a manipulação necessária ao contrato; a masculinidade de ambas as figuras sugere uma relação cultural com o assédio e o cavalheirismo. Também são masculinas as figuras relativas ao saber, os doutores santos, e ao poder, corporificado em Jesus Cristo.

Sem pretensões de exaustividade, termino este percurso como um peregrino que faz uma pausa restauradora. O estudo, aqui apenas esboçado, longe de ser um texto definitivo, deve ser entendido como um convite à investigação dessa peça que, resistindo a meio milênio, ainda instiga pelo que tem, sob a aparente simplicidade, uma nota de mistério.

\section{Referências}

CEIA, Carlos. Sobre o conceito de alegoria. Matraga. Lisboa. Universidade Nova. Portugal, 1998. Disponível em: <http://www.pgletras.uerj.br/matraga/nrsantigos/matraga10ceia.pdf $>$ Acesso em 11 ago 2018.

FONTANILLE, Jacques; ZILBERBERG, Claude. Tensão e significação. Trad. Ivã Carlos Lopes, Luiz Tatit e Waldir Beividas. São Paulo: Discurso Editorial: Humanitas/FFLCH/USP, 2001.

GÓIS, Damião de. Crónica de Dom Manuel. Lisboa : Off. de Miguel Manescal da Costa, 1749. GREIMAS, Algirdas Julien; COURTÉS, Joseph. Dicionário de semiótica. São Paulo: Contexto, 2008.

GREIMAS, Algirdas Julien; FONTANILLE, Jacques. Semiótica das paixões: dos estados de coisas aos estados de alma. Trad. Maria José Rodrigues Coracini. São Paulo: Ática, 1993.

SOCIEDADE BIBLICA DO BRASIL. A Bíblia sagrada: antigo e novo testamento. 2.ed. São Paulo: Sociedade Biblica do Brasil, 1993.

VICENTE, Gil. Copilaçam de todalas obras de Gil Vicente a qual se reparte em cinco liuros. O primeyro he de todas suas cousas de deuaçam. O segundo as Comedias. O terceyro as Tragicomedias. No quarto as Farsas. No quinto às obras meudas. - Vam emmendadas polo Sancto Officio como se manda no cathalogo deste Regno. - Lixboa : por Andres Lobato, 1586. - Auto da Alma. Porto: Porto Editora. s.d. [Biblioteca Digital. Coleção Clássicos da 


\section{Literatura Portuguesa.]}

ZILBERBERG, Claude. Elementos de semiótica tensiva. Trad. Ivã Carlos Lopes, Luíz Escreve

Tatit, Waldir Beividas. São Paulo: Atelíe Editorial, 2011. 